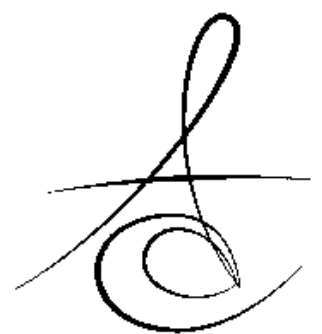

\title{
İMPLANT TEDAVİSİNİN PROGNOZUNU ETKİLEYEN LOKAL RİSK FAKTÖRLERİ
} LOCAL RISK FACTORS AFFECTING THE PROGNOSIS IN IMPLANT THERAPY

\author{
Dt. Elif PEKER
}

Prof.Dr. İnci Rana KARACA ${ }^{\#}$

Makale Kodu/Article code: 1498

Makale Gönderilme tarihi: 24.01 .2014

Kabul Tarihi: 07.02.2014

\section{ÖZET}

Modern Diş Hekimliğinin amacl; stomatognatik sistem atrofisi, hastalıkları ve yaralanmaları gibi durumlarda normal fonksiyon, estetik ve rahatlığı restore etmektir. Estetik bölgelerde implant tedavisi yapılacak vakalarda, risk faktörlerinin tedavi öncesinde dikkatlice değerlendirilmesi ve hastaya özel bazı kısıtlamaların tespiti son derece önemlidir. Bir ya da daha fazla lokal risk faktörünün bulunduğu bazı hastalarda mükemmel bir sonuç alınması her zaman mümkün değildir. Bu derlemede lokal risk faktörlerinin dental implant tedavisinin başarısına olan etkisi değerlendirilmiş ve göz önünde bulundurulması gereken kriterler anlatılmaya çalışılmıştır.

Anahtar Kelimeler: diş implantasyonu, risk faktörleri, periodontit

Dental implantların eksik dişlerin protetik restorasyonunu destekleme amaçlı kullanımları 1960'ların başından itibaren literatürde rapor edilmiştir. Günümüz pratiğinde klinisyen ve hasta dental implant tedavisinin başarısını, fonksiyonun sürekliliği ve nihai estetik sonuç referansları ile değerlendirmektedir ${ }^{1}$. Dental implant başarısının insidansında birçok faktörün potansiyel etkisi olduğu gösterilmiştir. Bu faktörler lokal veya sistemik faktörler olarak ikiye ayrılabilir ve bunlar implant tedavisinin erken ya da geç fazını etkileyebilir. Lokal risk faktörü; implant bölgesinde ve implanta komşu dişler seviyesinde başarılı bir osseointegrasyona ve dental implant restorasyonuna risk oluşturan herhangi bir durumdur ${ }^{1}$. Bu derlemede amaç, birçok potansiyel lokal risk faktörünün hem implantın prognozu ve başarısı gibi primer sonuçları üzerine, hem de dişeti çekilmesi, sondlamada kanama ve proksimal marjinal kemik kaybı gibi sekonder sonuçları

\section{ABSTRACT}

The aim of modern dentistry is to restore function, aesthetics and comfort, regardless of the stomotognatik system atrophy, diseases and injuries. Careful evaluation of the risk factors and patientspecific determination of some of the restrictions is extremely important prior to implant treatment in aesthetic areas. In some patients with one or more local risk factor is not always possible to get an excellent result. In this review local risk factors on the success of dental implant treatment were evaluated and it is tried to explain the criteria to be taken into consideration.

Key Words: dental implantology, risk factors, periodontitis

üzerine etkilerini tanımlamaktır. Göz önünde bulundurulan lokal risk faktörleri; interdental alan, enfekte bölgeler, yumuşak doku kalınlığı, keratinize yumuşak dokunun kalınlığı, kemik kalitesi ve miktarı, implant stabilitesi, periodontitistir.

\section{İnterdental Alan}

İnterdental alana uygun olmayan genişlikte implant yerleştirilmesinin interdental papil oluşumuna negatif etkisi sonucunda kötü bir estetik sonuç doğacağından, bu önemli bir risk faktörüdür ${ }^{1}$. Esposito ve ark., implant gövdesinin dişe horizontal mesafesinin $3 \mathrm{~mm}$ 'den az olması ile komşu dişte kemik kaybı arasında güçlü bir ilişki olduğunu rapor etmişlerdir ${ }^{2}$. Başka benzer bir çalışmada Krennmair ve ark., anterior ve posterior bölgelerdeki krestal kemik kaybı miktarlarının birbirinden önemli derecede farklı olduğunu, anterior bölgede proksimal kemik kaybını horizontal mesafenin önemli derecede etkilediğini rapor etmişlerdir $^{3}$. Elde edilen bu sonuç, otörleri dar horizontal

* Gazi Üniversitesi, Diș Hekimliăi Fakültesi, Aăız Diș Cene Hastalıkları ve Cerrahisi Anabilim Dalı 
mesafeli vakalarda papil koruyucu cerrahi metodlardan yararlanmaya teşvik etmiştir. Tarnow ve ark. yaptıkları çalışmalarda, papillanın yeterli seviyedeki idamesi için implantlar arasında mezio-distal olarak minimum $3 \mathrm{~mm}$ kemik bulunması gerektiğini, bu mesafenin $3 \mathrm{~mm}$ 'den az olduğu durumlarda krestal kemik kaybının 1.04 $\mathrm{mm}, 3 \mathrm{~mm}$ 'den fazla olduğu durumlarda ise $0.45 \mathrm{~mm}$ olduğunu rapor etmişlerdir ${ }^{4,5}$. Sınırlı interdental alan varlığında daha küçük çapta implantların kullanılması göz önünde bulundurulmalıdır ${ }^{6}$. Küçük çaplı implantlar dar alanlar ve ince kretler için yararlıdır ancak zayıftırlar ve aşırı yüklemelerde mekanik ve biyolojik olarak başarısızlığa uğrayabilirler ${ }^{7}$. Ayrıca yeterli horizontal mesafe; implantlar ve komşuluğundaki dişler arasında uygun kemik ve yumuşak doku kalınlığı oluşması, protetik parçaların birbirine olumsuz etkisi olmaması, hastanın protezini etkili olarak temizleyebilmesi için gereklidir. Komşu doğal diş ve implant arasında minimum $1 \mathrm{~mm}$ ya da tercihen $2 \mathrm{~mm}$ kemik bulunmalıdır. İmplantın boyun bölgeleri arasında ideal olarak $3 \mathrm{~mm}$ olmak üzere 2 mmden az olmamak koşuluyla bir miktar mesafe bulunması tavsiye edilir ${ }^{8,9}$. Bunun nedeni birçok sistemde abutmentların implant boyun kısmından daha büyük olması ve restorasyonun iyi bir dişeti profili oluşturmak için çapının daha geniş dizayn edilmesidir. İmplantın boyun bölgesinden daha dar çapta bir abutment ile bağlanması daha fazla yumuşak doku alanı sağlar ve bu teknik "platform switching' olarak adlandırılır. Atieh ve ark.nın 1239 implantı ve 10 adet çalışmayı içeren derlemelerinde, "platform switch"li implantların çevresinde önemli derecede az kemik kaybı olduğu ve bu cevabın özellikle platform "switch"in $0.4 \mathrm{~mm}$ ya da daha fazla olduğunda geliştiğini bildirmişlerdir ${ }^{10}$. Bu bilgiler göz önüne alındığında, implantların birbirine çok yakın yerleştirilmesinin yumuşak doku ve oral hijyeni ne derece riske attığı daha kolay anlaşılacaktır ${ }^{11}$.

\section{Enfekte Bölgeler}

İmmediat implant yerleşiminin en popüler endikasyonu, enfekte bölgelere yapılan immediat yerleşimdir. Periapikal lezyonlu insan dişlerinde yapılan çalışmalarda implantların sonuçlarından elde edilen veriler sınırıdır ${ }^{1}$. Bir hayvan çalışmasında immediat implant yerleşiminin periapikal olarak enfekte bölgelerde kontraendike olmadığı sonucuna varılmıştır ${ }^{12}$. Quirynen ve ark.ları çekim sonrası arta kalan ya da komşu dişte var olan endodontik bir lezyonun erken implant kaybına sebep olabileceğini öne sürmüşlerdir.
Ayrıca implant yapılmadan önce çekilen dişlerin etrafında endodontik lezyonun var olmasının apikal periimplantitis meydana gelen implantların kaybolma insidansını 3 kat artırdığını rapor etmişlerdir ${ }^{13}$. Başka bir çalışmada 2 ay sonunda \%92'den \%100'e kadar implant başarı oranı rapor edilmiştir. Takip periyodu kısa olmasına rağmen, otörler başarı oranının enfekte olmayan bölgelerle kıyaslanabilir olduğunu belirtmişlerdir ${ }^{1}$. Elde edilen sonuçlara dayanarak, periapikal granülom geçmişi olan bölgelerin implant yüklemesinden önce çeşitli radyografilerle incelenmesi gerektiği sonucuna ulaşılabilir ${ }^{8}$. Başarılı bir sonuç elde etmek için bu yöntemin tamamen debridman yapılan bölgeleri ve primer stabiliteye ulaşılabilen implantları gerektirdiği vurgulanmaktadır. Bu teoriye dayanarak apikal patolojisi olan vakalarda gecikmiş yükleme yapılması gibi daha konservatif yaklaşımlar düşünülebilir ${ }^{14,15}$.

\section{Yumuşak Doku Kalınlığı}

Kois, 2001 yılında gingival biyotipi kalın ya da ince olarak sınıflandırmıştır. Bu sınıflamaya göre kalın gingival biyotip, daha fazla fibrotik doku, vaskülarizasyon ve altında daha kalın bir sert doku sağlarken, ince biyotip daha az kemik desteği ve vaskülarizasyona sahiptir $^{16}$. Yumuşak doku kalınlığı açısından, ince doku biyotipinin mevcut olduğu bölgelerde dişeti çekilme riskinin fazla olduğu bildirilmiştir. Ancak dişeti çekilmesi, mevcut kemik ve implantın 3 boyuttaki pozisyonu gibi çeşitli durumlara da bağlıdır ${ }^{1,8,16}$. Evans ve Chen yaptıkları bir çalışmada immediat yerleştirilen implantların estetik sonuçlarını değerlendirmişlerdir ${ }^{17}$. İnce biyotipteki dokuda özellikle implantlar bukkal bölgeye doğru yerleştirildiğinde, dişeti çekilme oranı kalın biyotipteki dokulara göre daha fazla bulunmuştur. İmplantın komşuluğundaki cep derinliği direkt olarak kemik üzerinde mevcut olan yumuşak doku kalınlığı ile ilişkilidir. Yumuşak doku kalınlığı 4 mm'den az olduğunda implant etrafındaki cep derinliği ideal derinliğinden daha az olacaktır. İmplant yerleştirilmesinden önceki yumuşak doku kalınlığı değişkendir ve özellikle maksillada 6 mm'den fazla olabilir. Bu durumda gingivoplasti yapılabilir. Birinci aşama implant cerrahisi esnasında gereğinden fazla olan yumuşak doku kalınlığı azaltılabilir. Ancak iyileşme safhasında, yumuşak doku kalınlığı implant üzerinde bir tampon vazifesi görmesi açısından faydalı olabilir ve iyileşme boyunca implantın mikrohareket riskini azaltır ${ }^{18}$. 


\section{Keratinize Yumuşak Doku Genişliği}

İmplantların uzun dönem prognozunun artırıması açısından keratinize doku ile çevrili olması sıklıkla önerilmektedir ${ }^{1}$. Bouri ve ark.larının yaptıkları bir çalışmada, implantı çevreleyen keratinize doku genişliğinin 2 mm'den az olduğu grupta, 2 mm'den fazla olan gruba göre sondlamada kanama ve marjinal kemik kaybının önemli derecede artmış olduğu gözlenmiştir ${ }^{19}$. Başka bir çalışmada Wennström ve ark.ları, sondlamada kanama ölçütünü dikkate alarak mastikatör mukozanın atake kısımının yokluğunun, peri-implant yumuşak doku sağlığının idamesini riske atmadığı sonucuna varmışlardır ${ }^{20}$. Chung ve ark.ları ise keratinize yapışık yumuşak doku genişliğinin 2 mm'den az olduğu durumda inflamasyonun ve plak akümülasyonunun istatistiksel olarak önemli derecede yüksek olduğunu ancak yetersiz keratinize yapışık dişeti varlı̆ııın alveoler kemik seviyesine çok az etkisi olduğunu rapor etmişlerdir ${ }^{21}$. Roos-Jansaker ve ark.ları yaptıkları klinik çalışmada peri-implant lezyonların gelişiminde rol oynayan faktörleri belirlemişler ve keratinize mukoza miktarının mukozitis ve kemik kaybı ile önemli derecede ilişkili olduğunu bildirmişlerdir ${ }^{22}$. İmplant yerleştirilecek bölgede keratinize doku bandı olmadığında, flep kenarlarında cerrahi sonrası 24-48 saat içerisinde inflamasyon meydana gelecek ve gerilim kuvvetlerinin büyük kısmını kaybetmiş olacaktır. Bölgenin primer iyileşmesi açııından bu durum önemlidir ${ }^{23}$. Keratinize yumuşak dokunun cerrahi ogmentasyonu, bireyin plak kontrolüne faydası olabileceği düşünülen durumlarda yapılmalıdır 8 .

\section{Kemik Densitesi}

İmplantın başarılı integrasyonu için kemiğin kantitesi ve kalitesinin yeterli olması, aynı zamanda kemiğin kortikal ve trabeküler yapısının miktarı arasında bir denge olması gerekmektedir ${ }^{24}$. Literatürde implant başarı oranı ve kemik kalitesi birçok çalışmada ilişkilendirilmiştir. Engquist ve ark.larının yaptıkları bir çalışmada ikinci aşama implant cerrahisiden önce maksilla D4 kemikte (Tablo 1) \%20, mandibulada \%5 implant kayıp oranı rapor etmişlerdir ${ }^{25}$. Baqain ve ark., ise, D4 ve D1 kemikte (Tablo 1) daha yüksek kayıp oranı olduğunu bildirmişlerdir ${ }^{26}$. Jaffin ve Berman ${ }^{27}$ maksillada daha yumuşak kemik varlığında \%8.3 kaybı, Friberg ve ark.ları ${ }^{28}$ ikinci aşama implant cerrahisi öncesi maksillada, mandibulaya göre daha fazla ve yaklaşık \%4.8 implant kayıp oranı, Ouirynen ve $\operatorname{ark} \mid a r 1^{15}$ ise yine ikinci aşama cerrahi öncesi maksillada \%4.1 implant kayıp oranı bildirmişlerdir. Kourtis ve ark.larının yaptıkları çalışmada implant kaybı, maksillada mandibulaya göre istatistiksel olarak anlamlı derecede yüksek bulunmuştur ${ }^{29}$. İmplant kayıp oranında D1,D2 ve D3 kemikler (Tablo 1) arasında istatistiksel olarak önemli bir fark olmadığı, ancak D4 kemikte (Tablo 1) bu oranın istatistiksel olarak önemli derecede yüksek olduğu belirlenmiştir. Fugazzotto ve ark.ları ${ }^{30}$ Q4 kemiğe (Tablo 2) yerleştirilen 34 implant$\tan 22 \operatorname{sinin}$ kaybedildiğini, Sullivan ve ark.ları ${ }^{31}$ maksillada ikinci aşama cerrahi öncesi \%6.4, mandibulada \%3.2 kayıp oranı, Snauwert ve ark. ${ }^{32}$, zayıf densiteye sahip maksillada daha sık erken kayıpların olduğunu rapor ettikleri, Hutton ve ark.larının ${ }^{33}$ maksillada mandibulaya göre 9 kat daha fazla implant kayıp oranı oluşması nedeniyle Q4 kemiğin (Tablo 2) implant tedavisi için en yüksek riski oluşturduğunu belirledikleri, ayrıca ne tek başına kemik densitesinin ne de kemik hacminin, ancak her ikisinin kombinasyonunun implant başarısını ya da kaybını etkilediği bildirilmiştir. Bütün bu yapılan çalışmalar kemik kalitesini saptamak için kemik densitesinin subjektif klasifikasyonundan faydalanmışlardır. Ancak literatür incelendiğinde impIantların sonuçlarını değerlendirmek için kemik densitesinin standardizasyonuna açıkça intiyaç olduğu görülmektedir ${ }^{1}$.

Tablo 1. Misch'in sınıflandırması (kemiğin kalitatif sınıflandırması) ${ }^{18}$

\begin{tabular}{|l|l|}
\hline D1 & Yoğun kortikal kemik \\
\hline D2 & $\begin{array}{l}\text { Yoğun kortikal kemiğin sardığı ince trabeküler } \\
\text { kemik yapısı }\end{array}$ \\
\hline D3 & $\begin{array}{l}\text { İnce kortikal kemiğin sardığı, yeterli güçte yoğun } \\
\text { trabeküler kemik }\end{array}$ \\
\hline D4 & Kortikal kemik içermeyen yoğunluğu az kemik \\
\hline
\end{tabular}

Tablo 2. Leckholm ve Zarb'ın sınıflandırması ${ }^{51}$

\begin{tabular}{|l|l|}
\hline Q1 & Homojen kompakt kemik \\
\hline Q2 & Yoğun trabeküler kemik etrafında kalın kompakt kemik \\
\hline Q3 & $\begin{array}{l}\text { İyi dayanma gücüne sahip yoğun trabeküler kemiği } \\
\text { çevreleyen ince kortikal kemik }\end{array}$ \\
\hline Q4 & $\begin{array}{l}\text { Düşük yoğunlukta trabeküler kemiği çevreleyen ince } \\
\text { kortikal kemik }\end{array}$ \\
\hline
\end{tabular}




\section{İmplant Stabilitesi}

Literatürde implant stabilitesinin implantın başarısı üzerine etkisi incelenirken birden çok engelle karşılaşılmıştır. En önemlisi implant stabilitesinin objektif ölçümünün eksikliğidir ${ }^{8}$. Esposito ve ark.ları, immediat, erken ve konvensiyonel olarak yüklenen implantlar üzerine yapılan randomize kontrollü çalışmaları içeren bir derlemede, primer implant stabilitesinin başarılı bir immediat ya da erken yükleme için ön koşul olduğu neticesine varmışlardır ${ }^{34}$. Orenstein ve ark.larının yürüttükleri bir çalışmada, yerleştirilme esnasında klinik mobilitesi olan implantların 3 yıl sonrasındaki başarı oranı değerlendirilmiştir ${ }^{35}$. Başarı oranları implantı yerleştirmeden yüklemeye kadar \%78.8, protetik yüklemeden 3 yıl sonrasına kadar \%95.9 olarak rapor edilmiştir. Yerleştirme esnasında implantın mobil olması 3 yıllık idamesi ile önemli derecede ilişkili bulunmuştur. Molly'nin kemik densitesi ve primer stabiliteyi değerlendirdiği bir çalışmada implantın primer stabilitesinin ölçüldüğü farklı sistemler kullanılmıştır ${ }^{36}$. Yazar, Periotest (Medizintechnik, Gulden) cihazının primer stabilitenin belirlenmesi ya da tek bir ölçümle implant tedavisinin sonucu için herhangi bir tahmin değeri sağlaması konusunda kanıt olmadığı sonucuna varmıştır. Osstell(Integration Diagnostics) cihazı implant stabilitesini ölçmek için rezonans frekans analizini(RFA) kullanmaktadır ve yine yazar tek bir ölçümün implant tedavisi sonucu için herhangi bir tahmin değeri sağlamasına dair bir kanıt bulunmadığı çıkarımında bulunmuştur. Osseocare (Nobel Biocare) ise frezlerin giriş torkunun ölçümü ile çalışmaktadır ve yine primer stabilitenin belirlenmesi için bir değer sağladığı konusunda bir kanıt yoktur. Periotest değerleri ve kemik-implant bağlantısının değerlendirildiği bir çalışmada, cihazın implantı çevreleyen kemiğin özelliklerine duyarlı olduğu, kemikimplant bağlantısını herhangi bir şekilde değerlendirmediği bildirilmiştir ${ }^{37}$. Aynı çalışmada rezonans frekans analizinin, implantı çevreleyen kemiğe duyarlı olduğu ve implantın stabilitesini belirleyen ISQ (Implant stability quotient) değeri ile implantın anatomik lokasyonu arasındaki ilişkinin kanıtlandığı bildirilmiştir. Rezonans frekans analizinin belirli bir zaman periyodu içerisinde aynı implant üzerinde ya da aynı sistemin implantları üzerinde yapılan ölçümlerin karşılaştırılmasında kullanıldığı bazı araştırmacılar tarafından gösterilmiştir ${ }^{38}$. Bir çalışmada araştırmacılar, immediat yüklenen 344 implantın yerleştirilmesi aşamasında ve cerrahiyi takiben ölçüm yaparak değerlendirmişlerdir ${ }^{39}$. RFA ölçümleri ilk ayda implant stabilitesinde azalmayı ikinci ve üçüncü aylarda artışı göstermiştir. Türkyılmaz ve ark.ları cerrahi öncesi kemik densitesinin CT ile değerlendirildiği 230 implant bölgesini değerlendirmişlerdir $^{40}$. Osseocare cihazı kullanılarak giriş torku kaydedilmiş ve Osstell cihazı ile primer implant stabilitesi RFA ile ölçülmüştür. Otörler radyofrekans değerleri, kemik densitesi ve giriş torku değerleri arasında istatistiksel olarak önemli bir ilişki bulmuşlardır. İmplantın yapılmasından önce preoperatif CT alınmasının implantın stabilitesini öngörebilme açısından faydalı olabileceği sonucuna varmışlardır. Alsaadi ve ark.larının erken dönem implant kayıplarında lokal faktörleri inceledikleri bir çalışmada, implantların yerleştirilmesi aşamasında kaydedilen periotest değerlerinin erken dönem implant kaybı ile ilişkili olduğu belirtilmiştir $^{41}$. Düşük rijiditeyi gösteren yüksek Periotest değerleri oluştukça önemli derecede fazla implant kaybı meydana gelmiştir. Lachmann ve ark.ları sığır kemiği segmenti üzerinde yaptıkları deneysel bir çalışmada Osstell ve Periotest cihazlarının implant stabilitesini ölçmedeki güvenirliğini karşılaştırmışlar ve her iki cihazın da benzer derecede güvenilir olduğunu ve klinik kullanımının önerilebileceğini belirtmişlerdir ${ }^{42}$.

\section{Periodontitis}

Periodontal enfeksiyona bağlı olarak kaybedilen dişlerin yerine implant yapılması gitgide artan sayıda hasta tarafından tercih edilirken, periodontitis hikayesinin implant tedavisinin sonuçlarını etkileyip etkilemediği sorusu gündeme gelmektedir. Ong ve ark.ları yaptıkları sistematik derlemede periodontitis tedavisi gören bireylerin periodontal olarak sağlıklı bireylere göre daha fazla implant kaybı ve implant tedavisi komplikasyonu ile karşılaştığı sonucuna varılmıştır $^{43}$. Klokkevold ve Han, periodontal tedavi hikayesinin implantın idamesine negatif bir etkisi olmadığı ancak bu hastalarda uzun zaman periyodunda daha fazla komplikasyon ve düşük başarı oranı ile karşılaşılabileceği sonucuna varmışlardı ${ }^{44}$. Karoussis ve ark.larının derlemesinde periodontal tedavi hikayesi olan ve periodontal olarak sağlıklı olan hastalar karşılaştırıldığında gruplar arasında uzun ve kısa dönem implant idamesi açısından istatistiksel olarak anlamlı bir fark bulunmamıştır ${ }^{45}$. Başarı kriterleri değerlendirildiğinde ise, tedavi edilmiş kronik periodontitis hastaları, sağlıklı bireylerle karşılaştırıldığında 
uzun dönemde önemli derecede artmış cep derinliği, marjinal kemik kaybı ve yüksek insidansta periimplantitis sergilemiştir. Quirynen ve ark.larının yaptıkları sistematik derlemede, periodontitise yatkınlık ve peri-implantitis arasındaki ilişki araştırılmış, periodontal tedavi gören ve görmeyen hastalar karşılaştırıldığında periodontitis hikayesi olan hastalarda yüksek insidansta uzun dönem implant kaybı ve marjinal kemik kaybı rapor edilmiştir ${ }^{46}$. Schou ve ark.larının yaptığı bir çalışmada, periodontitise bağlı diş kaybı olan ve periodontal enfeksiyon dışında bir nedenden dolayı diş kaybı olan hastalar karşılaştırılmış, implantların 5 ve 10 yıl sonraki idamesi karşılaştırıldığında önemli bir fark bulunmamıştır ${ }^{47}$. Ancak 10 yıllık takip periyodunda periodontitise bağlı diş kaybı olan hasta grubunda daha fazla oranda peri-implantitis gözlenmiştir. Ayrıca bu hasta grubunda 5 yıllık takip periyodu sonucunda önemli derecede fazla marjinal kemik kaybı gerçekleşmiştir. Otörler periodontitise bağı diş kaybı olan hasta grubunda implantların idamesinin yüksek oranda olmasına rağmen, yüksek insidansta peri-implantitis gözlenmesinin implant tedavisinin uzun dönemdeki sonuçlarını tehlikeye atabildiği sonucuna varmışlardır ${ }^{48,49}$.

Branemarkla başlayan ve çok büyük oranda yapılan araştırmalar, implantların başarılı integrasyonunu tasdik etmelerine rağmen, başarılı başlangıç integrasyonundan yıllar sonra bile implant kaybının nedenleri hala anlaşılamamıştır. Cerrahi ve restoratif dental implant uygulayanların uzun bir zaman periyodu sonrası implant başarısı ya da kaybını analiz edebilmek için klinik verileri standardize şekilde biriktirmeleri önemlidir. Bu bilgi birikimi implant kaybının halen bilinmeyen nedenlerini anlamada yardımcı olabilir. Hastalara uzun dönem implant başarısını garanti ederken bu gibi lokal faktörler dikkate alınmalıdı ${ }^{50}$.

\section{KAYNAKLAR}

1. Martin W, Lewis E, Nicol A. Local risk factors for implant therapy. Int J Oral Maxillofac Implants 2009;24:28-38.

2. Esposito M, Ekestubbe A, Gröndahl K. Radiological evaluation of marginal bone loss at tooth surfaces facing single Branemark implants. Clin Oral Implants Res 1993;4:151-7.
3. Krennmair G, Piehslinger $E$, Wagner $H$. Status of teeth adjacent to single-tooth implants. Int J Prosthodont 2003;16:524-8.

4. Tarnow $D$, Elian $N$, Fletcher $P$, Froum $S$, Magner $A$, Cho SC, Salama M, Salama H, Garber DA. Vertical distance from the crest of bone to the height of the interproximal papilla between adjacent implants. Journal of Periodontolgy 2003; 74, 17858.

5. Tarnow DP, Cho SC, Wallace SS. The effect of inter-implant distance on the height of interimplant bone crest. Journal of Periodontology 2000;71, 546-9.

6. Lekholm $U$, Jemt $T$. Principles for single tooth replacement. In: Albrektsson T, Zarb G (eds). The Branemark Osseointegrated Implant, ed 1. Chicago: Quintessence,1989:117-26.

7. Tonetti SM. Determination of the success and failure of root-form osseointegrated dental implants. Adv Dent Res 1999; 13:173-80.

8. Malet J, Mora F, Bouchard P. Implant Dentistry at a Glance: Wiley; 2012.

9. Zetu $L$, Wang HL. Management of interdental/inter-implant papilla. J Clin Periodontol 2005; 32: 831-9

10. Atieh MA, Ibrahim HM, Atieh AH. Platform switching for marginal bone preservation around dental implants: a systematic review and metaanalysis. J Periodontol, 2010:81,1350-66

11. Palmer RM. Risk management in clinical practice. Dental implants. British Dental Journal 2010; 209:499-506.

12. Torabinejad M. Goodacre J. Endodontic or dental implant therapy: The factors affecting treatment planning. JADA 2006;137:973-7.

13. Quirynen M, Gijbels F, Jacobs R. An infected jawbone site compromising successful osseointegration. Periodontology 2000; 33:129-44

14. Dahlin C, Nikfarid H, Alsen B et al. Apical Periimplantitis:Possible predisposing factors, case reports and surgical treatment suggestions. Clin Imp Dent and Rel Res 2009; 11:3

15. Quirynen M, Vogels R, Alsaadi G, Naert I, Jacobs $R$, van Steenberghe D. Predisposing conditions for retrograde periimplantitis, and treatment suggestion. Clin Oral Implants Res 2005; 16:599608. 
16. Kois JC. Predictable single tooth periimplant esthetics. Five diagnostic keys. Compendium Continuing Education Dentistry 2001;22,199-208.

17. Evans CD, Chen ST. Esthetic outcomes of immediat implant placements. Clin Oral Implants Res 2008;19:73-80

18. Misch CE. Contemporary implant dentistry. 3rd ed. St. Louis: Mosby; 2007.

19. Bouri A Jr, Bissada N,Al-Xahrani MS,et al. Width of keratinized gingiva and the health status of the supporting tissues around dental implants. Int J Oral Maxillofac Implants 2008;23:323-6.

20. Wennström JL, Bengazi F, Lekholm U. The influence of the masticatory mucosa on the periimplant soft tissue condition. Clin Oral Implants Res 1994;5:1-8.

21. Chung DM, Oh TJ,Shotwell JL,et al. Significance of keratinized mucosa in maintenance of dental implants with different surfaces. J Periodontol 2006;77:1410-20.

22. Roos-Jansaker AM, Renvert $H$, Lindahl $C$,et al. Nine-to-fourteen-year follow up of implant treatment. Part 3:Factors associated with periimplant lesions. J Clin Periodontol 2006;33:296301.

23. Sadig W., Almas K. Risk factors and management of dehiscent wounds in implant dentistry. Implant Dent 2004;13:140-147.

24. Wood MR, Vermilyea SG. A review of selected dental literature on evidence-based treatment planning for dental implants: Report of the Committee on Research in Fixed Prosthodontics of the Academy of Fixed Prosthodontics. J Prost Dent. 2004;5:447-62.

25. Engquist B, Bergendal T, Kallus T. A retrospective multicenter evaluation of osseointegrated implants supporting overdentures. Int J Oral Maxillofac Impl. 1988;3:129-34.

26. Baqaina ZH, Moqbelb WY, Sawaira FA. Early dental implant failure: risk factors. Bri J Oral Maxillofac Surg. 2012;3:239-43.

27. Jaffin RA, Berman CL. The excessive loss of Branemark fixtures in the type IV bone, a 5 year analysis. J Periodontol. 1991;62:2-4.
28. Friberg $B$, Jemt $T$, Leckholm $U$. Early failures in 4641 consecutively placed Branemark dental implants, a study from stage I surgery to the connection of completed prostheses. Int J Oral Maxillofac Impl. 1988;3:129-34.

29. Kourtis S.G., Sotiriadou S, Voliotis S,et al. Private practice results of dental implants. Part 1: Survival and evaluation of risk factors. Implant Dent 2004; 13: 373-85.

30. Fugazzotto PA, Wheeler SI, Lindsay JA. Success and failure rates of cylinder implants in type IV bone. J Periodontol 1993;64:1085-7.

31. Sullivan DY, Sherwood RL, Collins TA. The reversetorque test: a clinical report. Int J Oral Maxillofac Implants. 1996;11:179-85.

32. Snauwaert K, Duyck D, van Steenberghe D. Time dependent failure rate and marginal bone loss of implant supported prostheses:a 15-year follow-up. Study Clin Oral Invest. 2000;4:13-20.

33. Hutton JE, Heath MR, Chai JY. Factors related to success and failure rates at 3 year follow up in an multicenter study of overdentures supported by Branemark implants. Int J Oral Maxillofac Implants. 1995;10:33-42.

34. Esposito M, Grusovin MG, Willings $M$,et al. The effectiveness of immediate, early and conventional loading of dental implants:A cochrane systematic review of randomized controlled clinical trials. Int J Oral Maxillofac Implants 2007;22:893-904.

35. Orenstein IH, Tarnow DP, Morris HF,et al. Threeyear post-placement survival of implants mobile at placement. Ann Periodontol 2000;5:32-41.

36. Molly L. Bone density and primary stability in implant therapy. Clin Oral Implants Res 2006;17:124-35.

37. Mathieua V, Vayrona R, Richardb G, Lambertb G, Nailia S, Meningaudc JP, Haiatd G. Biomechanical determinants of the stability of dental implants: Influence of the bone-implant interface properties. Journal of Biomechanics 2014;1:3-13.

38. Mesa F., Munoz R., Nogerol B,et al. Multivariate study of factors influencing primary dental implant stability. Clin. Oral Impl. Res. 19,2008;196-200.

39. Balshi SF, Allen FD, Wolfinger GJ, Balshi TJ. A resonance frequency analysis assessment of maxillary and mandibular immediately loaded implants. Int J Oral Maxillofac Implants. 2005;20:584-94. 
40. Turkyılmaz I, Tumer C, Ozbek EN, et al. Relations between the bone density values from computerized tomography, and implant stability parameters: A clinical study of 230 regular platform implants. J Clin Periodontol 2007;34:71622.

41. Alsaadi G, Quirynen M, Komarek A,et al. Impact of local and systemic factors on the incidence of oral implant failures, up to abutment connection. J Clin Periodontol 2007;34: 610-7.

42. Lachmann S, Laval JY, Jäger B, Axmann D, GomezRoman G, Groten M, Weber H. Resonance frequency analysis and damping capacity assessment. Part 2: peri-implant bone loss followup. An in vitro study with the Periotest and Osstell instruments. Clin Oral Implants Res. 2006 Feb; 17:80-4.

43. Ong CT, Ivanovski S, Needleman IG, et al. Systematic review of implant outcomes in treated periodontitis subjects. J Clin Periodontol 2008;35:438-62.

44. Klokkevold PR, Han TJ. How do smoking, diabetes, and periodontitis affect outcomes of implant treatment? Int J Oral Maxillofac Implants 2007;22:173-202.

45. Karoussis IK, Kotsovillis S, Fourmousis I. A comprehensive and critical review of dental implant prognosis in periodontally compromised partially edentulous patients. Clin Oral Implants Res 2007;6:669-79.

46. Ouirynen M, Abarca M, Van Assche N, et al. Impact of supportive periodontal therapy and implant surface roughness on implant outcome in patients with a history of periodontitis. J Clin Periodontol 2007;34:805-15.

47. Schou S, Holmsrtup $P$, Worthington $H V$, et al. Outcome of implant therapy in patients with previous tooth loss due to periodontitis. Clin Oral Implants Res 2006;17:104-23.

48. Heitz-Mayfield L, Huynh-Ba G. History of treated periodontitis and smoking as risks for implant therapy.Int J Oral Maxillofac Implants 2009; 24:3968.

49. Schou S. Implant treatment in periodontitissusceptible patients: A systematic review. J Oral Rehabil 2008;35:9-22.
50. Tolstunov L. Dental implant success-failure analysis: A concept of implant vulnerability. Implant Dent 2006;9:341-6.

51. Lekholm U, Zarb GA. "Patient selection and preparation," in Tissue Integrated Prostheses: Osseointegration in Clinical Dentistry, P. I. Brånemark, G. A. Zarb, and T. Alberktsson, Eds., Quintessence, Chicago, Ill, USA, 1985. pp. 199209.

\author{
Yazışma Adresi: \\ Dt. Elif PEKER \\ Gazi Üniversitesi \\ Diş Hekimliği Fakültesi \\ Ağız, Diş ve Çene Cerrahisi Anabilim Dalı \\ Emek/ANKARA \\ Tel: 031220343 36-45 \\ Gsm: 05302440114 \\ e-mail: peker_elif@yahoo.com
}

